\title{
(2) OPEN ACCESS \\ Social isolation and loneliness as risk factors for hospital admissions for respiratory disease among older adults
}

\author{
Feifei Bu $\odot,{ }^{1}$ Keir Philip, ${ }^{2}$ Daisy Fancourt ${ }^{1}$
}

- Additional material is published online only. To view please visit the journal online (http://dx.doi.org/10.1136/ thoraxjnl-2019-214445).

${ }^{1}$ Department of Behavioural Science and Health, University College London, London, UK ${ }^{2}$ National Heart and Lung Institute, Imperial College London, London, UK

\section{Correspondence to}

Dr Daisy Fancourt, Behavioural Science and Health, University College London, London, London, UK;

d.fancourt@ucl.ac.uk

Received 12 December 2019 Revised 19 February 2020 Accepted 16 March 2020 Published Online First 21 April 2020

\section{Linked}

- http://dx.doi.org/10.1136/ thoraxjnl-2020-214873

Check for updates

(C) Author(s) (or their employer(s)) 2020. Re-use permitted under CC BY-NC. No commercial re-use. See rights and permissions. Published by BMJ.

To cite: Bu F, Philip K, Fancourt D. Thorax

2020:75:597-599.

\begin{abstract}
Rising hospital admissions due to respiratory disease

(RD) are a major challenge to hospitals. This study explored modifiable social risk factors among 4478 older adults from the English Longitudinal Study of Ageing. Data were linked with administrative hospital records and mortality registry data (followup 9.6 years) and analysed using survival analysis accounting for competing risks. Living alone and social disengagement but not social contact or Ioneliness were associated with an increased risk of RD admissions, independent of socio-demographic, health and behaviour factors. Providing support for disengaged adults living alone who are at risk of RD admissions should be explored.
\end{abstract}

\section{INTRODUCTION}

Hospital admissions due to respiratory disease (RD) have major health and economic costs, ${ }^{1}$ are a central component of winter bed crises and emergency department congestion, and disproportionately affect more vulnerable parts of society such as older adults. ${ }^{2} \mathrm{RD}$ admissions have risen at three times the rate of all other reasons for hospital admission in recent years. ${ }^{2}$ So, more research into modifiable risk factors for RD hospital admissions is clearly warranted.

To date, little attention has been paid to social factors such as social isolation and loneliness, despite a strong rationale for their influence. Both social isolation and loneliness have been linked with an increased incidence of morbidity and mortality ${ }^{3}$ and are associated with decreased medication adherence and health-seeking behaviours, and increased hospital admissions for a wide range of conditions including mental illness and heart failure. ${ }^{45}$ Both are also linked with biological responses related to poorer outcomes, for example, increased systemic inflammation. ${ }^{6}$

Preliminary studies have suggested that, for people with chronic obstructive pulmonary disease (COPD), social isolation may increase risk of winter hospital admission with $\mathrm{RD},{ }^{7}$ while loneliness may increase emergency department presentation. ${ }^{8}$ In addition, social activities such as group singing and dance are increasingly utilised in COPD management, ${ }^{9}$ with suggestions that they may reduce health service utilisation and hospital admissions. ${ }^{10}$ However, this research area is under-developed and there is no evidence from longitudinal representative data.

\section{METHODS}

This study assessed the relationship between loneliness, three different aspects of social isolation and RD hospital admissions in a large cohort of older adults in the English Longitudinal Study of Ageing (ELSA): a nationally representative biennial panel study linked to admitted patient care (APC) data from NHS Hospital Episode Statistics. In order to consider the competing risk of death over the follow-up period, ELSA was linked with mortality data obtained from the UK National Health Service mortality registry. Using wave 4 data (2008/2009), 7270 of the 8780 participants provided consent to data linkage (87\%), $90 \%$ of these provided spirometric data and $68 \%$ of these provided full data leaving a sample of 4478 (online supplementary figure S1). The APC data were available until January 2018, providing a maximum follow-up of 9.6 years.

$\mathrm{RD}$ admissions were defined as admittance to hospital with a primary diagnosis of RD. Social isolation was measured as living alone or not (domestic isolation), frequency of social contact with children, relatives and friends (social contact), and frequency of engagement with community groups, volunteering or cultural activities (social engagement). Loneliness was measured using the three-item UCLA loneliness scale. Confounders included socio-demographic factors (gender, age, ethnicity, an index of socioeconomic status comprised of education, social class and wealth, and an index of indoor and outdoor respiratory-related living environment deprivation), health-related factors (pre-existing diagnosed and undiagnosed COPD assessed spirometrically, comorbidities and depression) and behavioural confounders (smoking, heavy drinking, diet and physical activity). Cox causespecific hazard (CSH) models were used to model the time from the baseline interview until the first RD admission within the follow-up, accounting for death as competing risks events. Main analyses were carried out in Stata V.15. Please see the supplement for detailed explanation of the variables and method.

\section{RESULTS}

Demographics are shown in online supplementary table S1. 11\% of participants had a RD admission within the follow-up period (online supplementary figure S2). Table 1 presents the results from the CSH models fitted progressively. Living alone was associated with a greater hazard of RD 


\begin{tabular}{llll}
\hline $\begin{array}{l}\text { Table } 1 \\
(n=4478)\end{array}$ & Estimated HRs, $\mathrm{p}$ values and $95 \% \mathrm{Cl}$ from Cox models \\
\hline Model I & Model II & Model III & Model IV \\
\hline Living alone & & & \\
\hline 1.83 & 1.41 & 1.37 & 1.32 \\
$\mathrm{p}=0.000$ & $\mathrm{p}=0.002$ & $\mathrm{p}=0.004$ & $\mathrm{p}=0.012$ \\
\hline $\begin{array}{l}(1.49-2.24) \\
\text { Low social contact }\end{array}$ & $(1.14-1.75)$ & $(1.10-1.69)$ & $(1.06-1.64)$ \\
\hline 0.98 & 0.96 & 0.96 & 0.96 \\
\hline $\mathrm{p}=0.720$ & $\mathrm{p}=0.307$ & $\mathrm{p}=0.349$ & $\mathrm{p}=0.328$ \\
\hline$(0.90-1.07)$ & $(0.88-1.04)$ & $(0.88-1.05)$ & $(0.88-1.04)$ \\
\hline Social disengagement & & & \\
\hline 1.56 & 1.42 & 1.33 & 1.24 \\
\hline $\mathrm{p}=0.000$ & $\mathrm{p}=0.000$ & $\mathrm{p}=0.000$ & $\mathrm{p}=0.000$ \\
\hline$(1.42-1.71)$ & $(1.27-1.58)$ & $(1.20-1.48)$ & $(1.11-1.38)$ \\
\hline Loneliness & & & \\
\hline 1.05 & 1.08 & 0.96 & 0.95 \\
\hline $\mathrm{p}=0.271$ & $\mathrm{p}=0.091$ & $\mathrm{p}=0.362$ & $\mathrm{p}=0.317$ \\
\hline$(0.96-1.14)$ & $(0.99-1.18)$ & $(0.87-1.05)$ & $(0.86-1.05)$ \\
\hline
\end{tabular}

Model I was unadjusted. Model II controlled for socio-demographic confounders. Model III additionally controlled for health-related confounders. Model IV additionally controlled for behavioural confounders.

admissions even after adjusting for potential confounders. In the fully adjusted model (Model IV), people living alone had a 32\% higher hazard compared with those who lived with others $(\mathrm{HR}=1.32$, 95\% CI 1.06 to 1.64$)$. Social disengagement was also a predictor of RD admissions. One SD increase in social disengagement was associated with a $24 \%$ increase in the hazard of $\mathrm{RD}$ admissions $(\mathrm{HR}=1.24,95 \% \mathrm{CI} 1.11$ to 1.38). However, neither low social contact nor loneliness was associated with RD admissions. The estimated cumulative hazards by domestic isolation and social disengagement are presented in figure 1.

Sensitivity analysis found very similar results when using multiple imputation (online supplementary table S2). Treating deaths from RD without a hospital admission $(n=15)$ as RD admissions did not materially affect results (online supplementary table S3), nor did excluding people who had RD admissions in the previous 5 years (online supplementary table S4), or isolating the sample to individuals with acute RD admissions (online supplementary table S5). There was no evidence that findings were moderated by gender (online supplementary table S6) or pre-existing RD conditions (online supplementary table S7).

\section{DISCUSSION}

Overall, our results are broadly supportive of earlier research suggesting that aspects of social isolation, but not subjective loneliness, are associated with an increased risk of hospital admission. ${ }^{5}$ Potential mechanisms for the association between social isolation and RD admissions include a higher risk of being physically inactive and smoking among people who are socially isolated, less social pressure to seek medical attention early in the development of a RD and biological factors including isolation-related inflammation. Further, living alone is associated with poor health, disability and the risk of falls; hence, clinicians may admit patients due to increased discharge risks.

Our findings that social contact is not protectively associated could be because social contact carries increased risks of contagious respiratory conditions, more so than living with somebody (where there is a restricted germ pool) or social engagement (which might not involve close person-to-person contact in the same way as seeing family or friends socially). This hypothesis, however, remains to be explored further.

The main strengths of this study include the use of a largescale representative survey linked to administrative records with an almost 10-year follow-up and the consideration of a comprehensive range of identified confounding factors. However, as an observational study, causality cannot be assumed. Measurement error or unidentified confounders may affect results.

In conclusion, older adults living alone with existing lung conditions may benefit from additional targeted community support to try and reduce the risk of hospital admissions. The roll out of social prescribing schemes may present opportunities for referring these individuals to social engagement
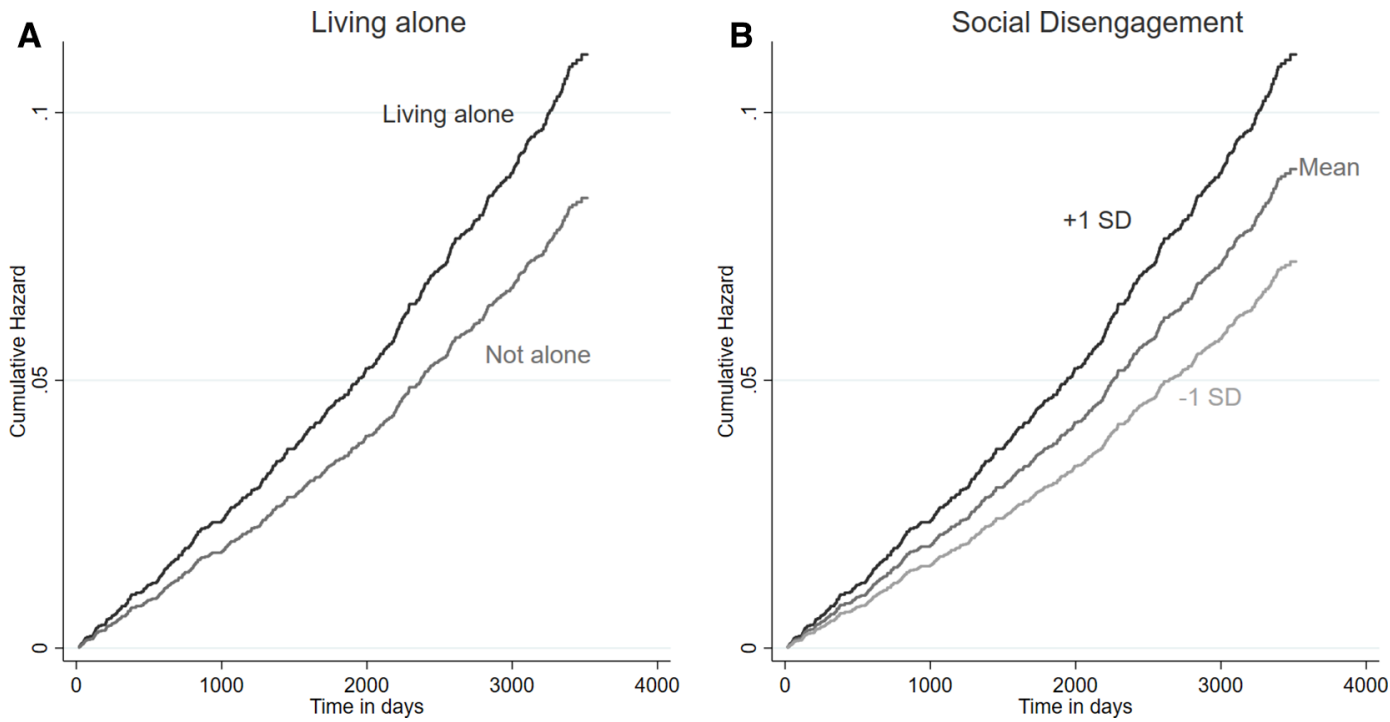

Figure 1 Estimated cumulative hazards by living alone and social disengagement. 
community activities.

Twitter Keir Philip @keirphilip

Acknowledgements The English Longitudinal Study of Ageing was developed by a team of researchers based at the University College London, NatCen Social Research, the Institute for Fiscal Studies and the University of Manchester. The data were collected by NatCen Social Research.

Contributors DF conceived the idea for this study. DF, FB and KP conducted the data analyses. The initial draft of the manuscript was produced by FB. DF, FB and KP were involved in interpreting the results and writing the manuscript. All authors read and approved the final manuscript.

Funding This research was supported through a grant from the Leverhulme Trust [PLP-2018-007]. KP was supported by the Imperial College Clinician Investigator Scholarship. DF was supported by the Wellcome Trust [205407/Z/16/Z]. The funders had no role in study design, data collection and analysis, decision to publish or preparation of the manuscript. The funding for English Longitudinal Study of Ageing is provided by the National Institute on Aging [R01AG017644] and a consortium of UK government departments coordinated by the Economic and Social Research Council.

Competing interests None declared.

Patient consent for publication Not required.

Ethics approval Ethics approval for ELSA was granted by the National Research Ethics Service.

Provenance and peer review Not commissioned; externally peer reviewed.

Open access This is an open access article distributed in accordance with the Creative Commons Attribution Non Commercial (CC BY-NC 4.0) license, which permits others to distribute, remix, adapt, build upon this work non-commercially, and license their derivative works on different terms, provided the original work is properly cited, appropriate credit is given, any changes made indicated, and the use is non-commercial. See: http://creativecommons.org/licenses/by-nc/4.0/.

\section{ORCID iD}

Feifei Bu http://orcid.org/0000-0003-2060-3768

\section{REFERENCES}

1 Trueman D, Woodcock F, Hancock E. The battle for breath - the economic burden of lung disease. British Lung Foundation, 2016.

2 British Lung Foundation. Out in the cold: lung disease, the hidden driver of NHS winter pressure, 2017

3 Holt-Lunstad J, Smith TB, Baker M, et al. Loneliness and social isolation as risk factors for mortality: a meta-analytic review. Perspect Psychol Sci 2015;10:227-37.

4 Allardyce J, Gilmour $\mathrm{H}$, Atkinson J, et al. Social fragmentation, deprivation and urbanicity: relation to first-admission rates for psychoses. Br J Psychiatry 2005; 187:401-6.

5 Rodríguez-Artalejo F, Guallar-Castillón P, Herrera MC, et al. Social network as a predictor of hospital readmission and mortality among older patients with heart failure. J Card Fail 2006;12:621-7.

6 Loucks EB, Berkman LF, Gruenewald TL, et al. Relation of social integration to inflammatory marker concentrations in men and women 70 to 79 years. Am J Cardiol 2006;97:1010-6.

7 Jordan RE, Hawker JI, Ayres JG, et al. Effect of social factors on winter hospital admission for respiratory disease: a case-control study of older people in the UK. $\mathrm{Br} J$ Gen Pract 2008:58:e1-9.

8 Marty PK, Novotny P, Benzo RP. Loneliness and ED visits in chronic obstructive pulmonary disease. Mayo Clin Proc Innov Qual Outcomes 2019:3:350-7.

9 Philip K, Lewis A, Hopkinson NS. Music and dance in chronic lung disease. Breathe 2019;15:116-20.

10 Lewis A, Cave P, Hopkinson NS. Singing for lung health: service evaluation of the British lung Foundation programme. Perspect Public Health 2018:138:215-22. 